\title{
ENTREVISTA COM ALEXANDER MEIRELES DA SILVA: ENTRE A UNIVERSIDADE, O MERCADO E O YOUTUBE
}

Enéias Tavares (UFSM)

Recebido em 03 set 2018. Enéias Tavares é professor de Literatura Clássica Aprovado em 23 out 2018. na Universidade Federal de Santa Maria, onde orienta trabalhos de pós-graduação sobre literatura fantástica e ministra a disciplina Escrita de Ficção. É pesquisador do Laboratório Corpus e do Programa de Pós-Graduação em Letras da UFSM, além de ser um dos coordenadores de projeto do Espaço Multidisciplinar da UFSM Silveira Martins. Integra também o GT da ANPOLL "Vertentes do Insólito Ficcional" e o Grupo de Pesquisa "Nós do Insólito: Vertentes da Ficção, da Teoria e da Crítica", grupo certificado pela UERJ junto ao Diretório de Grupos do CNPq. De ficção, publicou pela editora LeYa "A Lição de Anatomia do Temível Dr. Louison", primeiro volume de Brasiliana Steampunk, e pela editora Avec publicou "Guanabara Real - A Alcova da Morte". O primeiro foi finalista do Prêmio Argos de Melhor Romance de 2014 e o segundo ganhou o Prêmio Le Blanc de Melhor Romance Fantástico de 2017 e o Prêmio Ages de Melhor Romance Juvenil. De crítica, organizou ao lado de Gisele Biancalana e Mariane Magno dois volumes de "Discursos do Corpo na Arte" (Editora da UFSM, 2014 e 2017). Junto de Bruno Matangrano é também o responsável pela exposição "Fantástico 
Brasileiro", exposição que compreende uma história da literatura fantástica brasileira desde o século XIX até a contemporaneidade e que se tornou livro em 2018 pela editora Arte \& Letra. Brasiliana Steampunk enquanto série transmídia já ganhou card game, audiolivro, suplemento escolar e estão em produção uma história em quadrinhos e uma série audiovisual. Além deste trabalho, Tavares pesquisa storytelling transmídia e ministra workshops sobre escrita criativa e gerenciamento de projetos culturais, além de assinar a coluna sobre escrita criativa "Bestiário Criativo" e a webcomic "A Todo Vapor!" no portal CosmoNerd. 


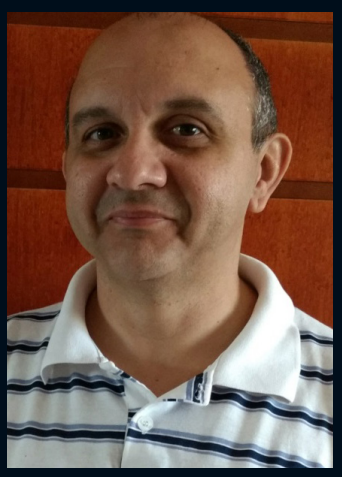

A distância entre a pesquisa acadêmica e o público leitor instaurou uma dificuldade tanto à popularização das ciências humanas em nosso país como ao acesso à educação superior por parte de muitos jovens. Comumente, se reproduz o preconceito de que a universidade está encerrada nela própria, de que sua reflexão é hermética ou então, de que ela é exclusivamente voltada aos "já iniciados". $\mathrm{Na}$ contracorrente dessa visão, tão prejudicial aos dois lados da balança, encontramos professores que têm trabalhado incansavelmente pela formação de jovens leitores, pela democratização da leitura e pela diminuição das barreiras que separam a universidade do grande público. Alexander Meireles da Silva integra esse admirável grupo.

Por anos, Alexander tem atuado em duas frentes bem importantes. A primeira delas é acadêmica, sendo responsável por orientações de mestrado e doutorado, pela escrita de artigos científicos dedicados ao insólito literário e pela organização de eventos voltados a esse tema, em especial na Universidade Federal de Goiás, onde atua desde 2009. A segunda é sua atuação como prefaciador de livros, tendo em seu currículo obras como Carmilla: A Vampira de Karnstein (Hedra, 2010), Contos Clássicos de Vampiros: Byron, Stoker e Outros (Hedra, 2010) e $O$ Fantástico: Procedimentos de Construção Narrativa em H.P. Lovecraft (Dialogarts, 2017). De sua produção acadêmica, consta também a organização dos volumes Estudos do Gótico (Editora Dialogarts, 2017) e Tessituras Literárias: Cultura, Identidades e Outras Artes (Editora Mercado de Letra, 2017), além de dezenas de artigos críticos em revistas e periódicos. Especificamente dentro do seu campo de atuação no ensino, também é autor do livro Literatura Inglesa para Brasileiros: curso completo de literatura e cultura inglesa para estudantes brasileiros (Editora Ciência Moderna, 2005). 
Não satisfeito, Alexander iniciou em 2016 uma importante ação direcionada a outra frente: o Youtube. Criador e apresentador do Fantasticursos, Meireles tem produzido vídeos sobre conceitos, obras e autores regularmente relacionados ao fantástico, dentro e fora do Brasil. Com bom humor, simpatia e respeito aos autores e suas obras, bem como à sua recepção, ele tem levado a essa plataforma um conteúdo acessível e divertido, sempre com o rigor crítico e teórico que lhe são característicos como pesquisador e estudioso.

Nesta entrevista por e-mail, tive o prazer de conversar com Alexander sobre os bastidores de seu canal, a importância da literatura para a formação de jovens leitores e os desafios de fazer conviver a tripla carreira de educador, pesquisador e youtuber. Para um acadêmico e ficcionista como eu, saber como um profissional como Alexander organiza sua vida - e sua produção! - será de grande ajuda.

P.: Olá, Alexander. Primeiramente, gostaria de parabenizar-te por tua produção e carreira. Para nós, é de grande incentivo vermos o que tens feito pela literatura e pelo estudo acadêmico em nosso país, um país tão múltiplo em perspectivas culturais e também em carências educacionais. Eu gostaria de começar pedindo que falasses um pouco de ti antes de te tornares professor. Tu sempre gostaste de literatura fantástica ou, como muitos de nós, te tornaste um leitor através de outras textualidades como revistas e quadrinhos?

R.: Agradeço e fico extremamente lisonjeado pelo convite e pelas palavras gentis. A admiração é mútua. Na verdade, meu contato com o Fantástico aconteceu em diferentes frentes. Meu pai me presenteou, quando eu era criança, com uma 
coleção de 4 livros da Disney que hoje foram repassados aos meus dois filhos nos quais você encontra os textos dos contos de fadas versão Disney, mas também diversas outras obras literárias e narrativas que já tinham sido adaptadas por eles. Então tinha Mary Poppins, Zorro, Robin Hood, Poliana, dentre várias outras histórias. Tendo nascido em 1972, também faço parte de uma geração que teve contato com séries de TV brasileiras e internacionais que marcaram gerações. O meu primeiro contato com mitologia grega, por exemplo, foi em uma das aventuras da adaptação televisiva do Sítio do Pica Pau Amarelo. Tive a felicidade de crescer nos anos 80 e assistia Ultraman no fim da manhã, Simbad e o olho do tigre (1977), Conan, O Bárbaro (1982) e Inimigo Meu (1985) na mesma semana na Sessão da Tarde e filmes de Drácula com Christopher Lee e Godzilla no SBT na parte da noite. Todo esse repertório foi essencial para a construção da minha nerdice. Já no início da adolescência, lembro do impacto da leitura dos romances de Vinte Mil Léguas Submarinas, de Júlio Verne (devo ter lido cinco vezes) e Um Cântico para Leibowitz, de Walter M. Miller Jr. (era diferente de toda a Ficção Científica que eu tinha lido e assistido até então).

P.: Como foi tua formação, tanto na graduação quanto na pósgraduação? Foi o caminho óbvio passar de uma coisa a outra ou uma decisão posterior, quando já estavas pensando em oportunidades profissionais?

R.: Desde o início, em 1994, no Bacharelado e Licenciatura em Inglês e Literaturas na UERJ, eu mirava dar aulas de Literatura Inglesa e Norte-americana, justamente para dar vazão à paixão 
por todo aquele universo que fez parte da minha infância e adolescência. Assim, foi natural ao término da Graduação fazer a Especialização em Literaturas de Língua Inglesa em 1998 e em 2001 entrar na primeira turma de Mestrado em Literaturas de Língua Inglesa, também na UERJ. Aí comecei a dar aula em cursos de Letras de faculdades particulares no Rio de Janeiro nas áreas de Língua Inglesa e Literaturas. Em 2004, para diversificar o olhar acadêmico, fui fazer Doutorado em Literatura Comparada na UFRJ sob a orientação do professor Eduardo Coutinho. Em todas essas etapas, o Fantástico sempre foi o foco das pesquisas.

P.: Podes nos falar um pouco sobre seus projetos na UFG? Um dos desafios da vida acadêmica é muitas vezes aproximar a pesquisa de pós-graduação da nossa atuação na graduação. Essa também é uma dificuldade tua?

R.: Desde que ingressei em 2009 na UFG, na regional da cidade de Catalão no Sudeste Goiano, venho alternando projetos que trabalham com diferentes aspectos do Fantástico. O primeiro foi a abordagem da alteridade nas diferentes vertentes do Fantástico e atualmente tenho trabalhado nas novas configurações e manifestações do fantástico contemporâneo, como o New Weird, o Slipstream e outras expressões. Considerando que os alunos não têm uma disciplina voltada exclusivamente para a Literatura Fantástica na grade curricular (o que seria um sonho), tento aproximar a pesquisa da PósGraduação dentro da Graduação por meio das disciplinas de Literatura Inglesa e Literatura Norte-americana, abordando autores e obras que são essenciais para o cânone literário dos 
países, ao mesmo tempo em que evidenciam a importância do Fantástico neste processo.

P.: Tu tens uma carreira também como prefaciador. Primeiramente, como vês a importância de, como professor, estares também inserido no mercado editorial? Como críticos, é sempre uma grande barreira partirmos da publicação em periódicos acadêmicos para publicações no grande mercado literário. Achas que essa relação entre universidade e mercado é boa ou ainda há o que melhorar nela?

R.: Essa relação não é apenas boa, mas necessária porque faz circular os saberes acadêmicos fora da esfera das instituições de ensino, tornando esse saber de fato útil para o público e não apenas algo de deleite intelectual para um público específico e restrito. Lembro e gosto de lembrar que sou Servidor Público e, portanto, devo servir ao público que se interessa pelo que pesquiso. O que tem de melhorar, e muito, é a postura de segmentos da Academia que não enxergam ou teimam em não enxergar as mudanças implementadas pela tecnologia e especificamente pelas redes sociais na disseminação e circulação de conhecimentos e seu impacto na formação de leitores e também escritores. A Academia precisa se posicionar e ocupar o seu espaço neste outro mundo.

P.: Quando tiveste a idéia do canal Fantasticursos e como foi o desenvolvimento dele, da concepção até o lançamento? Como é a dinâmica de produção dos vídeos para o canal? Tu fazes tudo sozinho ou há a ajuda de orientandos, colegas e outros profissionais? 
R.: O Fantasticursos nasceu a partir das reuniões quinzenais que fazia com alguns alunos para discutir textos literários e críticos ligados ao Fantástico. Nestas ocasiões era frequente o pedido dos alunos e alunas para trazerem irmãos, sobrinhos e colegas que não estavam na faculdade para as conversas. Passei a pensar quantas pessoas fora dos muros da universidade também gostariam de ter acesso às ricas discussões e pesquisas que circulavam neste ambiente. Desta forma, em outubro de 2016 comecei o blog e o canal Fantasticursos e no início de 2017 também abri a página no Facebook. Comecei com um vídeo por semana enquanto fazia cursos e treinamentos para conhecer e dominar o básico relacionado a gravação, iluminação, roteiro e edição de vídeos, criação de blog, elaboração de posts para blog e Facebook e como fazer lives, dentre outras coisas. Este é um universo muito pautado pela imagem e não queria fazer algo que desse a impressão de amadorismo, o que poderia gerar uma rejeição por parte das pessoas. Estava ciente de que estava entrando em um terreno onde ninguém me conhecia e que é dominado por rostos e personalidades jovens. Em média, cada vídeo, que ao final fica entre 6 a 8 minutos, porque acima disso é difícil manter o interesse, leva cerca de 8 horas para ficar pronto desde a ideia até ir pro youtube. A partir do tema, que muitas vezes é sugerido pelos inscritos, eu monto o roteiro buscando o balanço entre informações interessantes, rigor acadêmico e linguagem acessível. Tento gravar o material para dois vídeos no domingo e edito o que sai na terça-feira ao longo do domingo e trabalho no que sai na quinta-feira ao longo da terça e quarta. Tudo isso entre 
aulas na Graduação e na Pós-Graduação, reuniões, orientações de mestrandos e de Iniciação Científica, esposa e dois filhos pequenos de 9 e 11 anos com suas tarefas de casa. Editado o vídeo, insiro textos, imagens e trechos de filmes nele. Faço a renderização e o upload para o youtube. Por fim, faço a capa, penso no título, coloco as descrições e demais dados que o Youtube demanda para cada vídeo. Quando ele é publicado, posto no Facebook e no Twitter. Além dos vídeos, busco fazer uma live semanal para estreitar o contato com o público e para trazer personalidades do Fantástico de áreas diversas, como escritores, escritoras, editores, editoras, quadrinistas, pesquisadores e pesquisadoras. E sim, faço tudo sozinho.

P.: A pergunta que exige uma resposta, caro Alexander, sobretudo porque não há profissional hoje que não se digladie com o desafio da administração do tempo, especialmente aqueles inseridos na rotina exigente - e algo kafkiana - de grandes universidades: Como tu administras teu tempo a fim de manteres de forma equilibrada as carreiras de professor, pesquisador e youtuber?

R.: Tempo não é e nunca foi dinheiro. Tempo é vida. Assim, é imperativo não o desperdiçar com ações que vão nos afastar daquilo que realmente gostamos de fazer. É preciso um esforço para você não entrar em um ritmo produtivista em que a alimentação de dados do Lattes se torna uma obsessão. Seleciono as chamadas de artigos e eventos que quero fazer e participar. Outra coisa é a rotina burocrática das instituições, de fato kafkianas. Na condição atual de chefe da Unidade de Letras só faço reuniões quando necessárias e com tempo para 
começar e acabar. Quer bater papo, vá para o bar. Lembro sempre o caso do publicitário Washington Olivetto que fazia reuniões de pé, para que o incômodo fizesse as pessoas serem práticas e objetivas. Em casa não assisto a TV e durmo tarde, aplicando o provérbio de Benjamin Franklin que passo aos meus alunos e alunas quando reclamam que precisam dormir: "Haverá tempo suficiente para dormir no túmulo".

P.: Por fim, caro Alexander, que conselho tu darias a jovens professores e críticos quanto à perspectiva futura da nossa profissão? E obviamente, o que sugeririas a profissionais jovens ou também experientes que estão pensando em criar seu próprio canal?

R.: No caso de Mestrandos e Doutorandos, fomos acostumados, ou pior, adestrados a buscarmos a segurança dos concursos nas instituições públicas como forma de exercermos nossa paixão, mas o fato é que não há concursos suficientes para todos e todas. É preciso que estes profissionais busquem novas formas de se colocarem no mercado e o mundo online é uma saída. Por que vender o seu tempo, o seu conhecimento para uma instituição se você pode vendê-lo diretamente ao seu público? Hoje há tecnologia acessível e barata para isso. Mas leva tempo para você ser notado entre um grupo específico e demanda dedicação, persistência e resiliência. Isso também se aplica a quem quer começar um canal. Tudo se inicia pelo posicionamento. Você vai falar para quem? Vai falar o quê? Quer falar de livros? Dar dicas de leitura? O que você vai fazer para se diferenciar das centenas de canais semelhantes? Não é esperar que vão te notar. É preciso estratégia. Por que não 
um canal de livros escritos por mulheres? Ou mais específico ainda, por que não um canal de livros escritos por mulheres negras? No Brasil, pelo tamanho da população, qualquer nicho representa um público de milhares de pessoas, então há espaço para se fugir de coisas genéricas.

P.: Eu gostaria de agradecer muito por esta entrevista, Alexander, e por todo o trabalho que tens feito pelo "insólito literário", pela formação de novos leitores e pela divulgação de ações literárias diversas. Desejoso do nosso encontro no próximo "Vertentes do Insólito Ficcional", quando finalmente iremos nos conhecer pessoalmente. Um grande abraço! 